\title{
Article \\ Improved Recovery and Selectivity of Lanthanide-Ion-Binding Cyclic Peptide Hosts by Changing the Position of Acidic Amino Acids
}

\author{
Yoichi Hosokawa*(D), Ayako Oshima, Takaaki Hatanaka (D) and Nobuhiro Ishida*(D)
}

Toyota Central R\&D Labs., Inc., Nagakute 480-1192, Japan; aya-o@mosk.tytlabs.co.jp (A.O.); takaaki-h@mosk.tytlabs.co.jp (T.H.)

* Correspondence: e1305@mosk.tytlabs.co.jp (Y.H.); n-ishida@mosk.tytlabs.co.jp (N.I.)

check for

updates

Citation: Hosokawa, Y.; Oshima, A.;

Hatanaka, T.; Ishida, N. Improved

Recovery and Selectivity of

Lanthanide-Ion-Binding Cyclic

Peptide Hosts by Changing the

Position of Acidic Amino Acids.

Minerals 2022, 12, 148. https://

doi.org/10.3390/min12020148

Academic Editor: M Akbar

Rhamdhani

Received: 7 December 2021

Accepted: 21 January 2022

Published: 25 January 2022

Publisher's Note: MDPI stays neutral with regard to jurisdictional claims in published maps and institutional affiliations.

Copyright: (C) 2022 by the authors. Licensee MDPI, Basel, Switzerland. This article is an open access article distributed under the terms and conditions of the Creative Commons Attribution (CC BY) license (https:// creativecommons.org/licenses/by/ $4.0 /)$.

\begin{abstract}
The development of an effective host molecule to separate lanthanide (Ln) ions and a method for predicting its guest recognition/self-assembly behavior based on primary chemical structures are highly sought after in both academia and industry. Herein, we report the improvement of one-pot Ln ion recovery and a performance prediction method for four new cyclic peptide hosts that differ in the position of acidic amino acids. These cyclic peptide hosts could recognize $\mathrm{Ln}^{3+}$ directly through a 1:1 complexation-precipitation process and exhibited high $\mathrm{Lu}^{3+}$ selectivity in spite of similar ion size and electronegativity when the positions of the acidic amino acids were changed. This unpredictable selectivity was explained by considering the dipole moment, lowest unoccupied molecular orbital, and cohesion energy. In addition, a semi-empirical function using these parameters was proposed for screening the sequence and estimating the isolated yields without long-time molecular dynamics calculations. The insights obtained from this study can be employed for the development of high-performance peptides for the selective recovery of Ln and other metal ions, as well as for the construction of diverse supramolecular recognition systems.
\end{abstract}

Keywords: lanthanide ions; cyclic peptide; complexation; precipitation; dipole moment; frontier orbital; cohesion energy

\section{Introduction}

Lanthanides are indispensable for applications in advanced materials; therefore, a cost-effective recovery process with low energy expenditure is required to meet the rapidly increasing demand for these elements [1]. We recently reported a lanthanide ion mineralization peptide (Lamp1) with a cyclic structure that was inspired by natural mineralization, such as the pearl formation of pearl oysters [2]. Lamp1 could directly recover lanthanide ions $\left(\mathrm{Ln}^{3+}\right)$ as precipitates in water under ambient conditions in a one-pot, environmentally friendly, and low-energy process, without the use of organic solvents or column chromatography. Furthermore, using a genetic recombination technique, we have created functional silk fused with Lamp1 and proven the direct recovery of $\mathrm{Ln}^{3+}$ using silk materials [3]. The major driving force of Lamp1 in $\mathrm{Ln}^{3+}$ recognition is the electrostatic interactions from the side-chain $\mathrm{COOH}$ moieties of the acidic amino acids (AAs), namely aspartic acid (D) and glutamic acid (E). The precipitation is driven by self-assembly, which is promoted by the hydrophobic nature of the formed Ln complex.

To date, various organic hosts for $\mathrm{Ln}^{3+}$ [4-8], peptide hosts for organic guests [9-11], peptide-transition metal complexes [12-16], and self-assembling systems [17-19] have been reported. In recent years, extended research on Ln porphyrins [20], lanthanide-based metal organic frameworks [21], lanthanide-based inorganic-organic hybrid materials [22], a cyclic peptide ligand for $\mathrm{Tb}$ ions through high-throughput screening [23], and a lanthanidebinding protein [24] have also been interesting. We have also used a lanthanide-binding 
tag (LBT) of a linear peptide that recognizes $\mathrm{Ln}^{3+}$ to report on the interaction mechanism between the binding affinity for each $\mathrm{Ln}^{3+}$ and the molecular structure of the LBT peptide [25].

As for the computational molecular design of peptides/metal-peptide complexes, simulations of a metal-peptide complexation process [26], the physical properties of a $\mathrm{Gd}^{3+}$ complex [27] $/ \mathrm{Eu}^{3+}$ peptide complex [28], the self-assembly behavior of peptides [29]/cyclic peptides [30], and the simulation of a lanthanide-binding coiled coil design [31] have been reported. More recently, cyclic peptide structure prediction using machine learning has been expected as a future screening/prediction method [32]. The simulation of the solution structure of peptides [33] and the solvent extraction of lanthanide ions [34] have also been reported.

However, to the best of our knowledge, the molecular design, $\mathrm{Ln}^{3+}$ recognition properties, and simulations of cyclic peptides that undergo a complexation-precipitation process (e.g., Lamp1) have not yet been reported. Although the self-assembly of peptidemetal complexes are known to play an important role in supramolecular systems, longtime MD (Molecular Dynamics) simulations required for analyzing this process remain challenging [17,35]. Even an MD simulation of a 27 tetra-peptide cluster formation in a $3 \times 10^{4}$ water molecules cell requires 5 months by a special-purpose MDGRAPE- 3 computer [36]. Our cyclic peptides contain 11 amino acids, except for 2-cysteine, which means that $11^{11}$ sequence patterns exist, so the application of such a high-cost MD simulation method for sequence screening/performance prediction is difficult. However, since a DFT calculation analyzing parameters such as molecular structure, bonding, electron negativity, dipole moment (DM), and HOMO (Highest Occupied Molecular Orbital) /LUMO (Lowest Unoccupied Molecular Orbital) can be carried out quickly using personal computers [37], the utilization of such parameters is expected as the candidates of the present screening method.

In this work, we evaluated the molecular recognition ability of cyclic peptide structures both experimentally and computationally. In order to understand the complexationprecipitation behavior by Lamp1 to improve the $\mathrm{Ln}^{3+}$ selectivity and recovery yield by Lamp1 (recovery yields for typical $\mathrm{Ln}^{3+}$ : La, 15\%; Dy, 27\%; and $\mathrm{Lu}, 38 \%$ ) [2] we focused on the positions of the acidic AAs in this study and designed four simple model peptides bearing three acidic AAs at different positions (Figure 1). Furthermore, we have tried to establish a low-cost and semi-empirical method, without a solvent molecule, to predict the recovery yield based on experiment results and the above parameters, analyzed by DFT (Density Functional Theory) calculation.

A
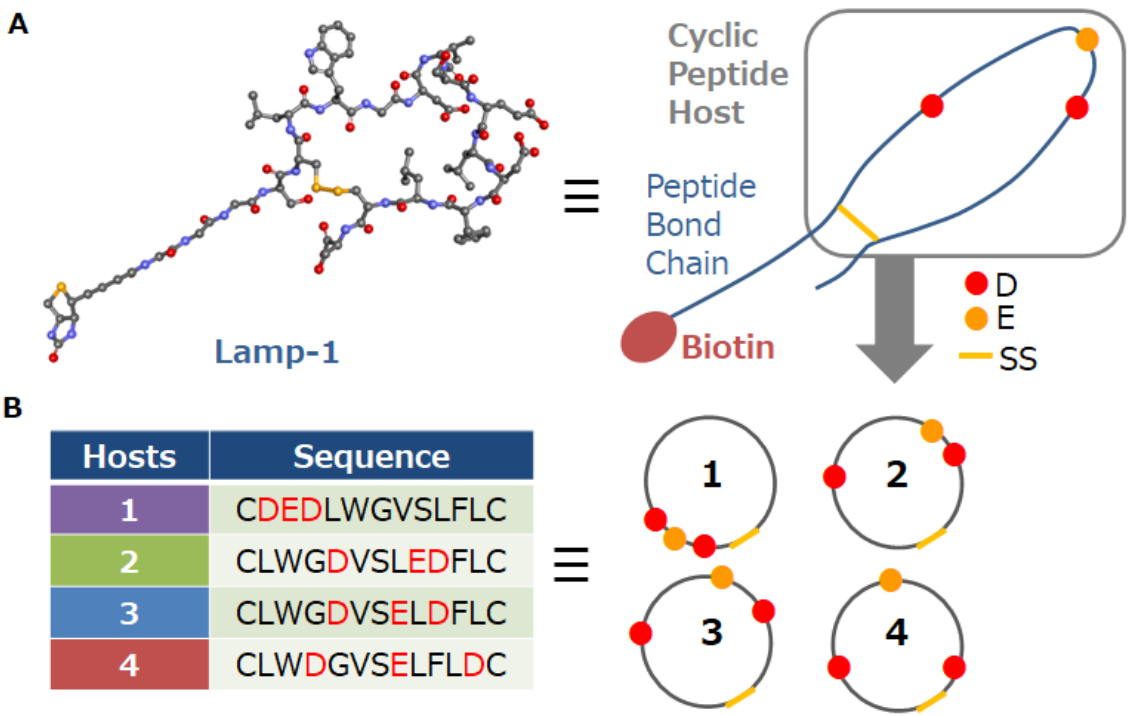

Figure 1. (A) Ball-and-stick model (left) and schematic representation (right) of Lamp1. (B) Sequences and schematic structures of cyclic peptide hosts 1-4. 
The sequence of the AAs (with the exception of the acidic AAs and cysteine SS bond) and the total number of AAs (13) were identical, and thus these hosts were structural isomers. The acidic AAs in model 1 were present in a continuous sequence $(2 \mathrm{D}, 3 \mathrm{E}$, and $4 \mathrm{D})$, those in model 2 (5D, 9E, and 10D) and model 3 (5D, 8D, and 10D) were distributed relatively more randomly, while those of model 4 were dispersed uniformly in the form of a stable tripod (4D, 8E, and 12D). The sequence of model 3 was the same as the cyclic peptide sequence of Lamp1.

Considering the pre-organization principle for optimizing a host structure for a guest [38], the recovery yields of the prepared hosts are expected to increase in the order $1<2<3<<4$ due to the strain-less three-coordination structure, while those of the typical $\mathrm{Ln}^{3+}$ ion are expected to increase in the order $\mathrm{La}^{3+}<\mathrm{Dy}^{3+}<\mathrm{Lu}^{3+}$ due to the hydrolysis property in neutral aqueous conditions; however, the yield difference should typically be small because of the small differences in the ion size (La-Lu: $\sim 0.03 \mathrm{~nm}$ ) and electronegativity (La: 1.08, Dy: 1.10, and Lu: 1.14). The above low Ln selectivity of Lamp1 (recovery yield: La, 15\%; Dy, 27\%; and Lu, 38\%) [2] seems to reflect those small differences and have reasonable values. It is unknown how the position of acidic AAs is effective for Ln selectivity; however, it should be effective for the improvement of the first complexation process. For the followed precipitation process, increases in self-assembly properties should have an important role.

Thus, based on the design concept as described above, we carried out a performance evaluation and simulation of complexation-precipitation processes of the four cyclic peptide hosts in Figure 1 with $\mathrm{La}^{3+}, \mathrm{Dy}^{3+}$, and $\mathrm{Lu}^{3+}$. Precipitation was induced in a manner similar to that in a previous study [2]. The precipitation yield as well as the structure/composition of the precipitation product should be altered by the metal ion concentration; accordingly, all experiments were carried out using 10 equiv. of metal ions (c.f., the peptide concentration) to ensure that the complexation reaction reached equilibrium. In addition, all experiments were carried out at $\mathrm{pH}$ 6.1, since lanthanide ions form metal hydroxides in an alkaline solution.

Regarding the recovery yield simulation, in the DFT calculation of a metal ion complex with polyethyleneoxide/crown ether, the large DM and concentrated LUMO on the metal atom of the complex indicate the stable complex formation [39]. Therefore, we have focused on the DM and LUMO of a Ln complex as important parameters in the complexation step. For the precipitation step, the cohesive energy (CE) between the Ln complexes is an essential driving force for precipitation by self-assembly.

Thus, we have developed a concept such as Equation (1), where the calculation of the recovery yield should contain DM, CE, and LUMO as the parameters, for example:

$$
\text { Simulated yield }=\mathrm{DM} \times \mathrm{LUMO} \times \mathrm{CE} \text {. }
$$

In reality, each parameter was compared to the recovery yield observed to give the corresponding function, and then the semi-empirical equation for calculation was fabricated based on the correlation function obtained.

\section{Materials and Methods}

\subsection{Experimental Section}

\subsubsection{Materials and Instrumentation}

All peptide hosts (as $\mathrm{HCl}$ salt, purity $>98 \%$ ) were purchased from GenScript (Tokyo, Japan), a custom peptide synthesis service. Reagent-grade $\mathrm{La}\left(\mathrm{NO}_{3}\right)_{3} \cdot 6 \mathrm{H}_{2} \mathrm{O}$, Dy $\left(\mathrm{NO}_{3}\right)_{3} \cdot 6 \mathrm{H}_{2} \mathrm{O}$, $\mathrm{NaOH}$, and ultrapure water were obtained from FUJIFILM Wako Pure Chemical (Osaka, Japan). $\mathrm{Lu}\left(\mathrm{NO}_{3}\right)_{3}$ was purchased from Sigma Aldrich (St Louis, MO, USA), and molecular-biology-grade MES (2-Morpholinoethanesulfonic acid) was obtained from Dojindo Laboratories (Kumamoto, Japan). All chemicals were used as received. Ultrasonic stirring for peptide solution preparation was performed by a NISSEI Corporation USS-1 ultrasonic stirrer (Tokyo, Japan). 
${ }^{1} \mathrm{H}$ nuclear magnetic resonance (NMR) spectra were acquired on a JEOL JMM-EX400 spectrometer (400 MHz, in DMSO (dimethyl sulfoxide)-d6, scan: 16) (JEOL Ltd., Tokyo, Japan). Attenuated total reflection Fourier transform infrared (ATR-FTIR) spectra were acquired on a Thermo Scientific Nicolet Avatar 360 FT-IR spectrometer (scan: 60, resolution: 8) (Thermo Fisher Scientific, Waltham, MA, USA). Electrospray ionization mass spectrometry (ESI-MS) using the liquid chromatography quadrupole time-of-flight mass spectrometry method (LC-QTOF-MS) was performed on an Agilent 6540 Q-TOF spectrometer (Agilent, Santa Clara, CA, USA) by diluting the DMSO solutions of the precipitate by 100 times using methanol (injection rate: $300 \mu \mathrm{L} / \mathrm{min}$; ionization: Duel-ESI; career gas: $\mathrm{N}_{2}$; temperature: $30{ }^{\circ} \mathrm{C}$; capillary voltage: $3500 \mathrm{~V}$; fragmentor voltage: $100 \mathrm{~V}$; and scan range: $m / z=20-1700$ ).

Scanning electron microscopy with energy-dispersive X-ray (SEM-EDX) studies were conducted on a Hitachi High-Technologies TM3000 microscope (Hitachi High-Technologies, Tokyo, Japan) in the same manner described in [2], and inductively coupled plasma optical emission spectrometry (ICP-OES) was performed on a RIGAKU CIROS 120 spectrometer for Ln ion concentration analysis (column: IonPac CG5A Guard column, CS5A analytical column (Thermo Scientific, Waltham, MA, USA); indicator reagent: 4-(2-pyridylazo) resorcinol (PAR); and elution rate: $1.2 \mathrm{~mL} / \mathrm{min}$ ). $\mathrm{Ln}$ ion concentration can be decided by the absorbance at $530 \mathrm{~nm}$ of a Ln-PAR complex [40-42]. Thermogravimetry-differential thermal analysis (TG-DTA) was performed on a Rigaku Thermo Plus TG8120 instrument (Rigaku, Tokyo, Japan) (career gas: air; max temperature: $800{ }^{\circ} \mathrm{C}$; and temperature rate: $\left.10{ }^{\circ} \mathrm{C} / \mathrm{min}\right)$.

\subsubsection{Precipitation of the Peptide Host-Ln Ion Complexes}

Each host $(26.9 \mathrm{mg}, 0.018 \mathrm{mmol})$ was dissolved in $62.5 \mathrm{mM}$ MES buffer of $\mathrm{pH} 6.1$ (60 mL, host concentration: $300 \mu \mathrm{M}$ ) using an ultrasonic stirrer. Following this, $0.06 \mathrm{mmol}$ (or $3 \mathrm{mM}$ ) Ln salt (La: $26.0 \mathrm{mg}$, Dy: $27.4 \mathrm{mg}$, and Lu: $21.6 \mathrm{mg}$; metal concentration: $3 \mathrm{mM}$ ) was added to a $30 \mathrm{~mL}$ screw-cap vial and an aliquot $(20 \mathrm{~mL})$ of the host solution (host: $8.98 \mathrm{mg}, 0.006 \mathrm{mmol}$ ) was added. After $12 \mathrm{~h}$, the resulting precipitates were separated by centrifugation (12,000 rpm, $2 \mathrm{~min})$, washed with MES buffer and pure water, and dried under air at room temperature for 2-3 d and subsequently under a vacuum at room temperature for $12 \mathrm{~h}$. The obtained white powders were soluble in DMSO but insoluble in water, methanol, ethanol, acetone, and acetonitrile.

\subsection{Computational Study}

\subsubsection{Environment, Software, and Methods}

ChemDraw Professional 15.1 (PerkinElmer, Waltham, MA, USA) was used to draw the chemical structures, the Chem3D 15.1 MM2 program (PerkinElmer, Waltham, MA, USA) was used for initial structure calculations, and the Chem3D 15.1 MOPAC 2016 program (MOPAC, Atlanta, GA, USA) was used for DM calculations [43]. All the software programs were run on a Dell Precision T7910 PC (CPU: Xeon E5-2630 v3 (2.40 GHz), RAM: 32 GB, and OS: Windows 7 Pro SP1) (Dell, Long Rock, TX, USA). The Materials Studio (MS) 7.0 DMol3 module (BIOVIA, San Diego, CA, USA) was used for LUMO calculations, and the 8.0 Amorphous Cell and Forcite modules (BIOVIA, San Diego, CA, USA) were used for cohesive energy (CE) calculations [44]. The basic calculation procedure of MS was performed according to the BIOBIA tutorial text [45]. All calculations were run on a remote server (CPU: Xeon E5-2690 × 2 (SandyBridge/ 8 core/2.90 GHz), RAM: 64 GB, InfiniBand: FDR 56 Gbps, and OS: RHEL6.1.).

\subsubsection{Initial Structure Determination of the Peptide-Ln Complex}

A peptide structure drawn by ChemDraw was pasted into Chem3D for MM2 optimization over 2-3 min to remove any initial structural overlap, since structural optimization does not reach completion when a lone peptide is present. Subsequently, a La ion was placed at the top, bottom, or center of the peptide ring plane. The La (atom type parameter: $\mathrm{La}^{3+}$ trigonal) ion was bonded to a COO group, and the structure was then optimized using 
MM2. The default parameters (job type: minimize energy) were used, and the optimization took $<15 \mathrm{~min}$. As a result, five model structures per host-La complex (i.e., a total of 20 models for the four hosts) were calculated. Finally, the complex structure that was expected to converge or the most stable structure based on the energy-structure plot was used as the initial structure for subsequent simulations. The Dy and Lu complexes were prepared by substituting La in the structure of the final La complex since those atom types are not equipped.

\subsubsection{Calculating the DM of the Peptide-Ln Complex}

MOPAC calculations [42] were performed on each MM2-optimized structure with the following parameters: type, minimize (energy/geometry); method, PM7; properties, dipole; and additional keyword, SPARKLE. All other parameters used were the same ones as the initial values/status. Although the structure optimization of the Dy compounds in MOPAC was terminated initially, the addition of the keyword 'SPARKLE' made this optimization possible.

\subsubsection{Calculating the LUMOs of the Peptide-Ln Complex}

MS DMol3 calculations [43,44] were performed on each MM2-optimized structure with the following parameters: task, energy; functional, GGA-BLYP; smearing, $0.1 \mathrm{Ha}$; and properties, orbitals, spin-unrestricted (applied only to the Dy ion). All other parameters used were the same ones as the initial values/status.

\subsubsection{Calculating the CE of the Peptide-Ln Complex}

MS Amorphous Cell calculations [43,44] were performed on the MM2-optimized structures with the following parameters: task, construction; quality, ultrafine; density, 1.5; loading, 2; and force field, universal. MS Forcite calculations were then performed on a cell containing two complex molecules using the following parameters: task, dynamics; quality, ultrafine; ensemble, NVT; thermostat, velocity scale; total simulation time, 50 ps; number of steps, 50,000; and frame output, every 50,000 steps. NVE operations were carried out using the following parameters: restart, ensemble, NVE; frame output, every 5000. The CE was finally calculated with the following parameters: task, cohesive energy density; quality, ultrafine; and include structure in study table. All other parameters used were the same ones as the initial values/status.

\subsubsection{Calculating the Simulated Yield}

The simulated yield was finally calculated by Equation (2) as follows:

$$
\text { Simulated Yield }(\%)=\text { YA } \times \text { LUMO }
$$

$\mathrm{YA}=(\mathrm{YD}+\mathrm{YC}) / 2$

$\mathrm{YD}=-9.1501(\mathrm{DM}$ value $)+165.08$

$\mathrm{YC}=0.0617$ (CE value $)^{5.9384}$

$\mathrm{LUMO}=1$ or 0.5

Here, YA is the average yield of YD and YC, which are the isolated yields expected from the relationship of DM or CE with the isolated yield, respectively. The LUMO was considered constant for the calculation and set to 1.0 for complexes with a concentrated LUMO on the metal ion and to 0.5 for complexes without a concentrated LUMO on the metal ion. The product of YA and the LUMO constant provides the simulated yield.

\section{Results and Discussion}

\subsection{Lanthanide Ion Recovery}

Slight precipitation was observed in the solutions of host peptides $\mathbf{1}$ and $\mathbf{2}$ (Figure S1a) upon the addition of $\mathrm{Ln}^{3+}$ ions. The solution of host peptide 3 became immediately cloudy, indicating precipitation, upon the addition of most of the $\mathrm{Ln}^{3+}$ ions, whereas the solution 
of host peptide 4 did not become cloudy in the presence of $\mathrm{La}^{3+}$ (Figure 2A). Under slightly acidic conditions, no precipitation was observed in the $\mathrm{Ln}^{3+}$ solutions in the absence of peptides, even after one month (Figure S1b). The precipitates were soluble in DMSO, and the presence of Ln in the precipitate was confirmed by SEM-EDX (Figure 2B).
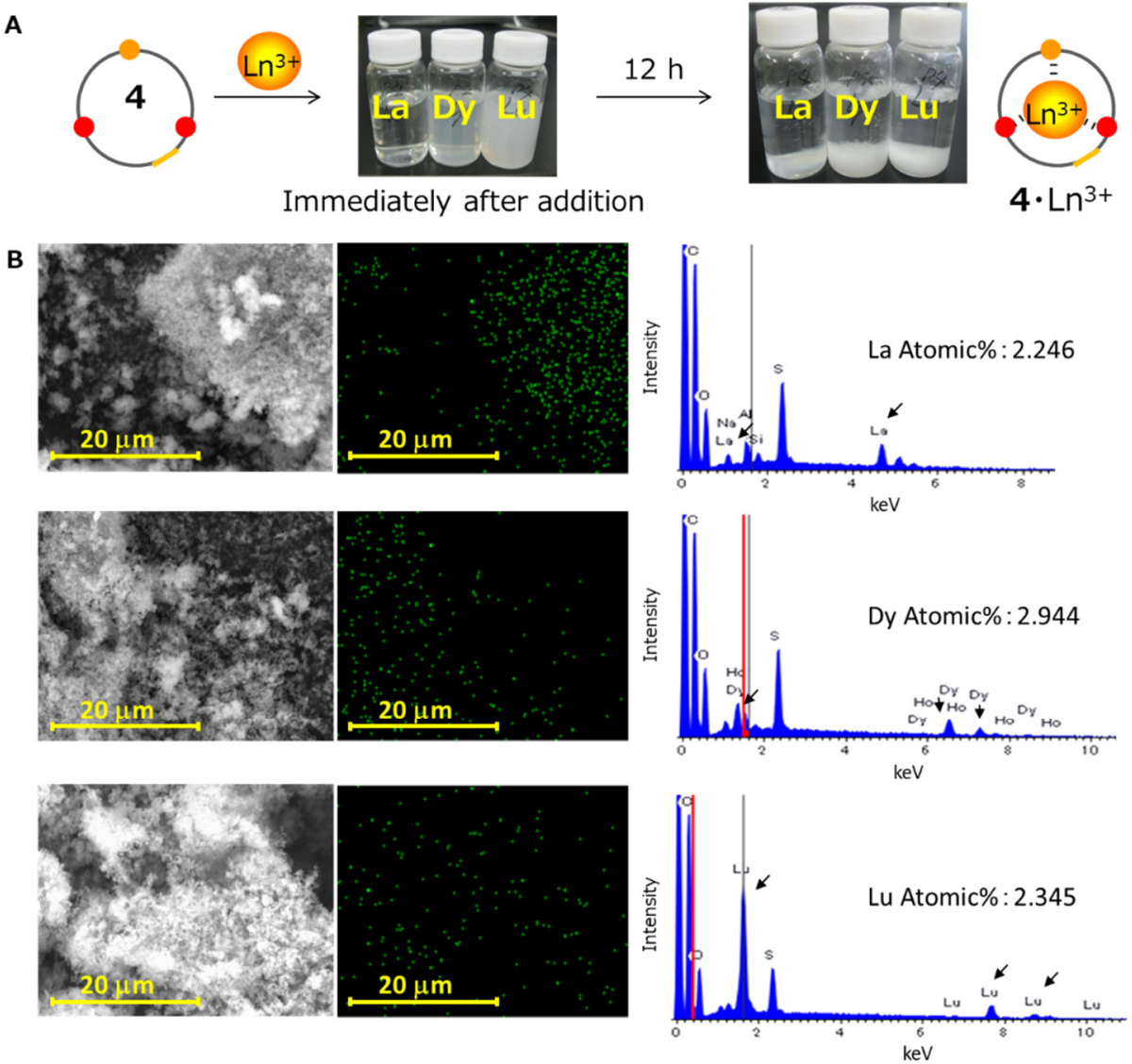

Figure 2. (A) Schematic representation of complex formation and photographs of the mixture of host 4 with $\mathrm{La}^{3+}, \mathrm{Dy}^{3+}$, and $\mathrm{Lu}^{3+}$. [Peptide] $=300 \mu \mathrm{M}$ and $\left[\mathrm{Ln}^{3+}\right]=3 \mathrm{mM}$ in $62.5 \mathrm{mM}$ MES buffer (pH 6.1). (B) SEM-EDX analyses of the precipitates from model 4: (La, Dy, and Lu). Scale bar: $20 \mu \mathrm{m}$.

After the complexation of peptide 4 with $\mathrm{Ln}^{3+}$, downfield shifts were observed in the ${ }^{1} \mathrm{H}$ NMR signals corresponding to the $\left(\mathrm{CH}_{2}\right) \mathrm{n}$ groups of the D/E side chains at $2.5 \mathrm{ppm}$, and the signal corresponding to the peptidic $\mathrm{NH}$ proton at $8.0 \mathrm{ppm}$ broadened following the addition of Lu (Figure S2a). This indicated the coordination of the D/E COO moieties to $\mathrm{Lu}^{3+}$ as well as the presence of weak interactions between the peptide main chain and the $\mathrm{Lu}$ atom. Furthermore, peaks corresponding to peptide 4 were mostly absent from the supernatant after Lu addition (Figure S2b), indicating almost complete precipitation.

In the IR spectra, small shifts were observed in the signals corresponding to peptides ( $1650 \mathrm{~cm}^{-1}$ (amide I, C=O) and $1540 \mathrm{~cm}^{-1}$ (amide II, N-CO)). Moreover, for the 3:1 D-Ln complex, symmetric signals from the coordinating side-chain $\mathrm{COO}$ group was previously observed at $1420 \mathrm{~cm}^{-1}$ [46]. For the peptide-Ln complexes prepared in this study, a new absorbance signal was observed in this wavenumber range, indicating the successful complexation with $\mathrm{Ln}^{3+}$ (Figure S3).

Furthermore, the ESI-MS analysis revealed a molecular ion peak corresponding to a 1:1 host-Ln complex, and the simulated MS spectra of this complex were fully correlated with the experimental data (Figure S4) [47]. Moreover, TG-DTA measurements also confirmed the formation of a 1:1 complex (Figure S5 and Table S1). Therefore, we concluded that the hosts form a 1:1 complex with $\mathrm{Ln}^{3+}$ through the coordination of the $\mathrm{D} / \mathrm{E}$ side-chain $\mathrm{COO}$ groups and weak interactions with the main-chain peptide bonds, leading to precipitation due to the hydrophobic interactions of the Ln complex. Further analyses, such as exam- 
ination of the soluble products, $\mathrm{pH}$ /concentration dependence, $\mathrm{CD}$ spectra, super-high magnetic field NMR spectra, and X-ray diffraction pattern, are being conducted.

The isolated yields (Figure $3 \mathrm{~A}$ and Table S2) were almost consistent with the $\mathrm{Ln}^{3+}$ concentrations in the supernatant, as determined by ICP-OES (Figure 3B and Table S3). For all the hosts, the Ln recovery increased in the order $\mathrm{La}<\mathrm{Dy}<\mathrm{Lu}$. The recoveries using peptides 3 and $\mathbf{4}$ were high, whereas those using peptides 1 and $\mathbf{2}$ were low. More specifically, peptide 4 showed a high recovery yield for Lu (>99\%), in contrast to Lamp1 (38\%), although the La and Dy recoveries were similar for both Lamp1 and peptide 4 . This indicated that the tripod arrangement of the acidic AAs is preferable for such recognition. The low isolated yield by peptide $\mathbf{1}$ was attributed to the low complex stability caused by the steric repulsion and strain of the $\mathrm{COO}$ groups. However, despite the similar sequences of peptides $\mathbf{2}$ and $\mathbf{3}$, the yield for peptide $\mathbf{2}$ was unexpectedly low.

A

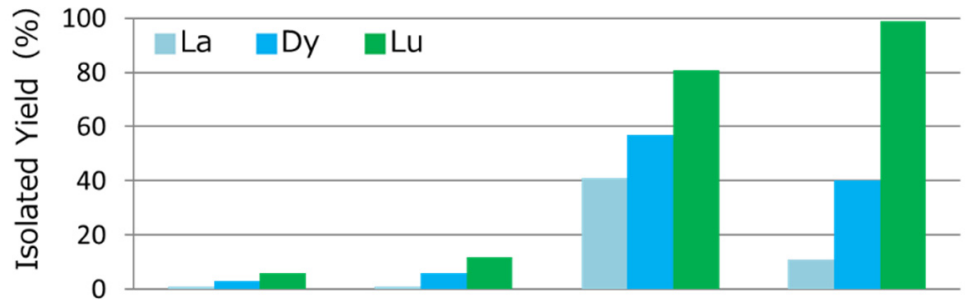

B

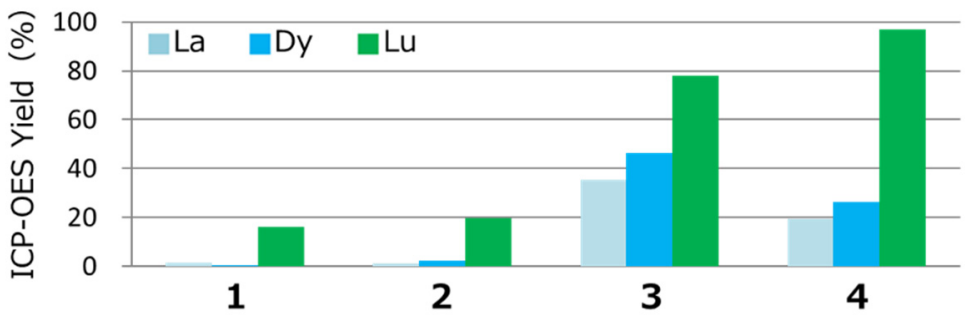

Figure 3. (A) Isolated yield of each Ln complex. Error: $\pm 3 \%$. (B) ICP-OES yield of each Ln complex.

In particular, peptide 3 (average recovery yield: $\mathrm{La}, 38 \%$; Dy, $62 \%$; and $\mathrm{Lu}, 80 \%$ ), with the same cyclic structure as Lamp1 (recovery yield: La, 15\%; Dy, 27\%; and Lu, 38\%) [2], exhibited a similar Ln selectivity; however, each yield was twice as much as that of Lamp1.

Peptide 4 (average recovery yield: La, 15\%; Dy, 33\%; and Lu, 98\%) produced an unexpectedly high Lu yield/selectivity due to the optimal ion size and electronegativity. It is also to be noted that peptide 4 exhibits improved not only recovery yield but selectivity for $\mathrm{Lu}^{3+}$ compared with Lamp1 (recovery yield: La, 15\%; Dy, 27\%; and Lu, 38\%) [2].

To understand these unpredictable selectivities and recoveries, and to predict the peptide structure with the highest selectivity for $\mathrm{Ln}^{3+}$, we next simulated the $\mathrm{Ln}^{3+}$ recovery process using the MOPAC program, in addition to carrying out DFT/MD calculations using the MS program [43-45].

\subsection{Prediction of Recovery Performance}

\subsubsection{Initial Structure Determination of the Peptide-Ln Complex}

The initial structure of each complex was determined based on the energy-structure plots using the MM2 calculations of five typical isomers (Figure 4 and Table S4), since additional calculations with unnatural metal positions for accuracy increasingly gave terminated or endless results. Owing to the small cyclic structure, the peptide chain skeleton in the metal complex is relatively rigid; therefore, there are limited possible conformations of the complex structure, as evident from the MM2 calculations (Figures S6-S9). As expected, a structure with a small volume (high density) was thermally stable. However, other structural features with respect to the total energy were not very clear. Although it may be possible to obtain a more stable structure through computationally demanding MD simulations, the development of a realistic rapid screening method is also important. We presumed that such a screening method would provide suitable starting structures before 
performing the MOPAC/DFT calculations. In the case of the straight peptide, the structure could not be optimized even in the MM2 calculations.

A

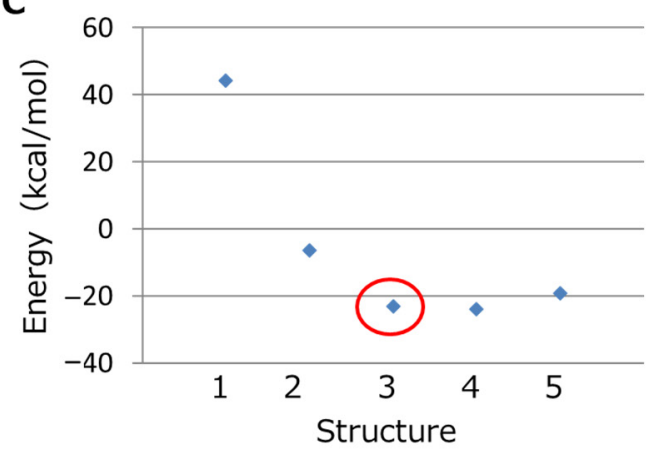

B

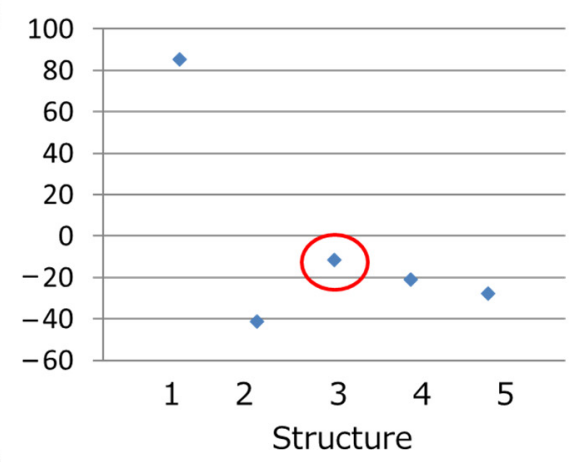

D

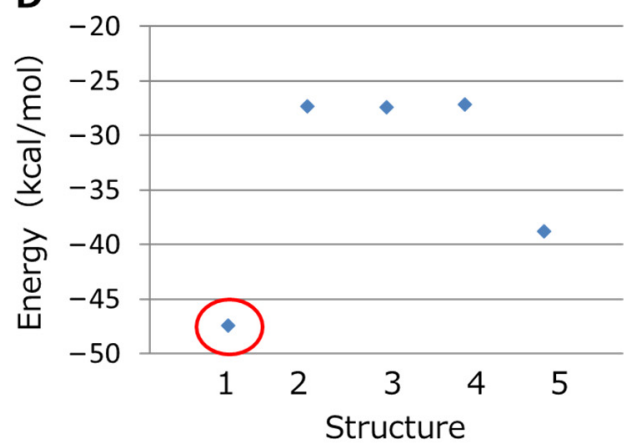

Figure 4. MM2 energy-structure plots for (A) host 1-La complex, (B) host 2-La complex, (C) host 3-La complex, and (D) host 4-La complex. The red circles indicate the data points of the structures used as the initial points for the DM, LUMO, and CE calculations.

The coordination number of lanthanide ions is high and changes from six to twelve based on the lanthanide species. Indeed, eight-coordinate species formed through interactions with amide oxygen atoms have been identified by single-crystal $\mathrm{X}$-ray structure analysis of a straight peptide-lanthanide complex [12]. The distance between the coordinating atom and Ln ion is approximately $2.3 \AA$, and no coordination to water was observed. However, for small cyclic peptides, such as those in the present study, the conformation was limited. All the amide $\mathrm{O}$ atoms are located far from the $\mathrm{Ln}$ ion; therefore, coordination was challenging and would have resulted in a large strain energy, rendering the system structurally and thermally unstable. Therefore, we selected the three-coordinate model, whereby the space was occupied by water molecules. Water was also detected in the TG-DTA measurements within 5 min (Figure S5).

\subsubsection{Calculating the DM and CE of the Peptide-Ln Complex}

The DM of the $4 \cdot \mathrm{Lu}$ complex was $7.52 \mathrm{D}$, which is relatively small compared to those of the other complexes prepared in this study (Figures 5A and S10). The DMs of peptides 3 and $\mathbf{4}$ were low for all the Ln ions, whereas those of peptides $\mathbf{1}$ and $\mathbf{2}$ were relatively large. Compared to the isolate yields, a small DM seems to have large isolated yield.

A d-orbital-type LUMO is formed on the Ln ion of the 4-Lu and 3-La/Dy complexes, and no other complex possessed the LUMO at this location (Figures 5B and S11).

The CE of 4-Lu was determined to be $3.48 \mathrm{MJ} / \mathrm{m}^{3}$, which was the highest among the CEs of the various complexes (Figures $5 \mathrm{C}$ and S12). In contrast, the CE of the highly flexible 1-Lu complex was only $0.45 \mathrm{MJ} / \mathrm{m}^{3}$, the lowest among those of the various complexes. The $\mathrm{CE}$ of polystyrene is $1.8 \mathrm{MJ} / \mathrm{m}^{3}$, so the value is an index if the simulated compound has precipitate formation properties. The complex dimer with a large CE probably forms a self-assembled structure with a small volume, because of which no extra space is available. 
Such a dense structure should immediately lead to precipitation. Indeed, the trend in the $\mathrm{CE}$ reflects the recovery trend appropriately.
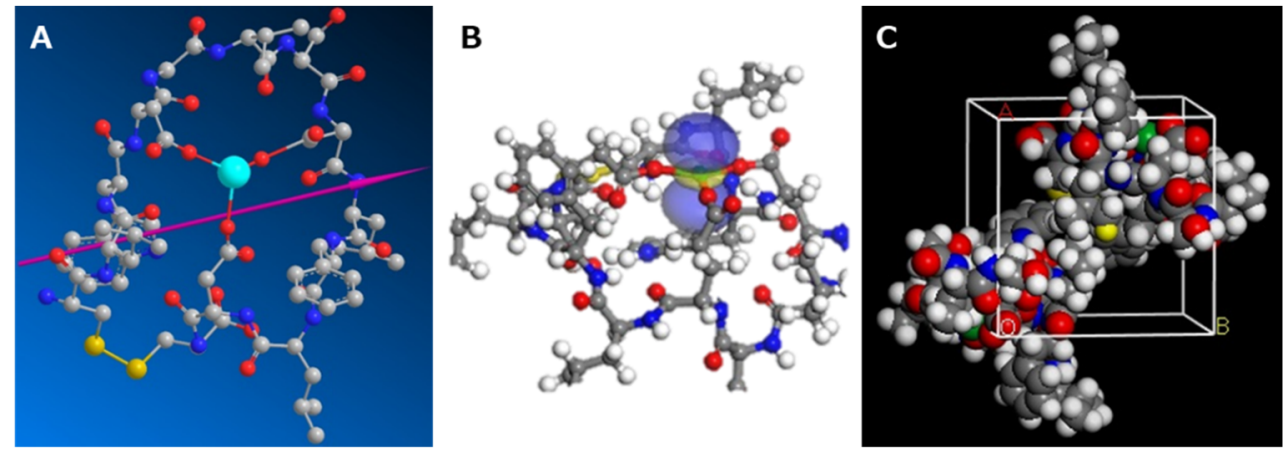

Figure 5. Simulation results for Ln recovery by peptide 4. The (A) DM vector, (B) LUMO, and (C) cohesive structure of $4-\mathrm{Lu}$.

Based on these simulation results, the observed recovery yields can be qualitatively explained. Complex 3-La is generated in a moderate yield (40\%) due to a relatively moderate-size LUMO on the La atom, an adequately small DM, and an inadequately low CE. Complex 4-Lu is generated in a high yield ( $>99 \%)$ because of the large-size LUMO on the $\mathrm{Lu}$ atom, a small $\mathrm{DM}$, and a large $\mathrm{CE}$, while complex 4-La is obtained in a low yield $(11 \%)$ due to the absence of the LUMO on the La atom and a large DM despite a high CE. Complexes 1-Ln or 2-Ln were also obtained in low yields $(<20 \%)$ owing to the missing LUMO on the Ln atom, large DMs, and low to moderate CEs.

\subsubsection{Calculation of the Simulated Yield}

Initially, to clarify the correlation between the DM or CE and the isolated yield, each $\mathrm{DM}$ or $\mathrm{CE}$ value was converted into the isolated yield (YD or YC) expected from the DM or $\mathrm{CE}$ calculations based on the statistical analysis of three typical DM or CE values (1-La, 3-Dy, and 4-Lu) (Figure 6A,B). Both DM and CE value should be greater than zero. For $\mathrm{YD}$, a smaller DM value resulted in a higher yield, and for $\mathrm{YC}$, a smaller $\mathrm{CE}$ value resulted in a lower yield. The DM data were approximated by applying the linear function, and the $\mathrm{CE}$ data were approximated using an exponential function.

Subsequently, the average yield (YA) of YD and YC were calculated (Table S5). The LUMO was then considered as a constant for the calculation and was set to 1.0 for complexes with a concentrated LUMO on the metal ion and to 0.5 for complexes without a concentrated LUMO on the metal ion. The product of YA and the LUMO constant provides the simulated yield.

Thus, the yield can be estimated from the DM, LUMO, and CE. Therefore, we attempted to derive a function for estimating the simulated yield based on these three parameters, as follows:

$$
\text { Simulated Yield }(\%)=\text { YA } \times \text { LUMO }
$$

$\mathrm{YA}=(\mathrm{YD}+\mathrm{YC}) / 2$

$\mathrm{YD}=-9.1501(\mathrm{DM}$ value $)+165.08$

$\mathrm{YC}=0.0617(\mathrm{CE} \text { value })^{5.9384}$

$\mathrm{LUMO}=1$ or 0.5

Here, YA is the average yield of YD and YC, which are the isolated yields expected from the relationship of DM or CE with the isolated yield, respectively. The LUMO value is kept constant at 1 for complexes with a LUMO on the metal atom and at 0.5 for complexes where the LUMO is not present on the metal atom. 
A

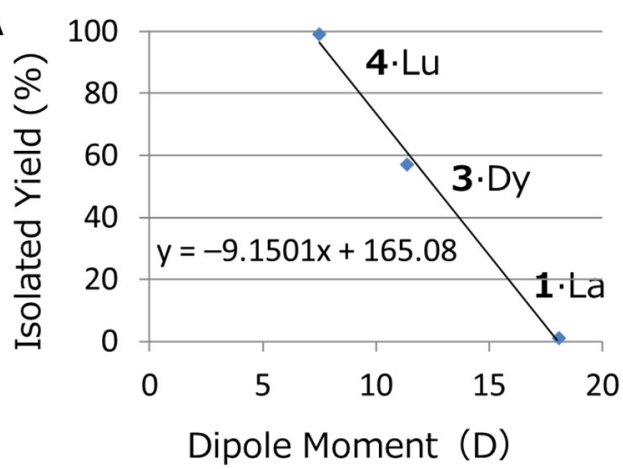

B

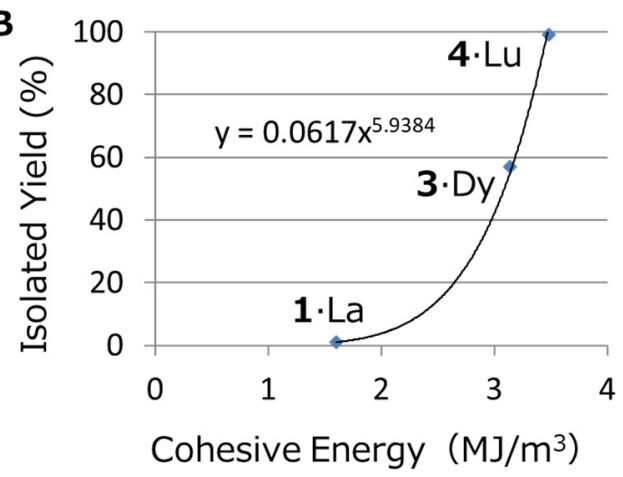

C

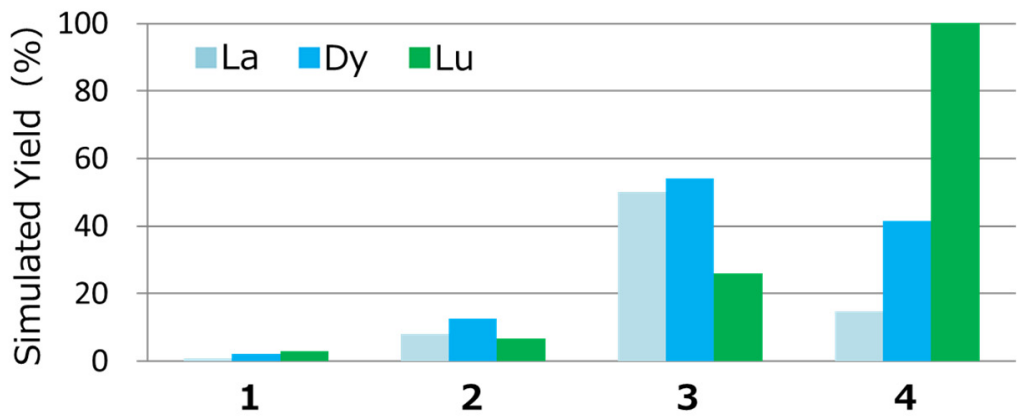

Figure 6. Top: statistical analysis graphs with approximate curves for the relationship between (A) DM and (B) CE with isolated yields using the data for 1-La, 3-Dy, and 4-Lu. Re-calculated YD and YC are shown in Table S5. (C) Simulated yield of each Ln complex.

Figure 6C and Table S6 show that the simulated yields roughly agree with the experimental results both qualitatively and quantitatively, with the exception of $2-\mathrm{Lu}$ and 3-Lu. It should be noted that the present simulation method has some limitations in that the solvent molecules were not included because of our development concept: a rapid screening method with low calculation costs. Consequently, more accurate results may be obtained using higher software versions or computationally demanding MD simulations, such as GROMACS, using solvent molecules. However, it is impractical to evaluate the performances of all the sequences. The total calculation time using the present strategy is $\sim 20$ min per complex (DM: $<5 \mathrm{~min}$; LUMO $<10 \mathrm{~min}$; and CE $5 \mathrm{~min}$ ). Therefore, this is a potential method for rapidly screening new peptide hosts.

Finally, in order to explore the next leading sequence candidates, the screening of other peptide structures by MM2 calculation was carried out. For example, the acidic AA position of peptide 4 is the 4 th, 8 th, and 12th position, and the acidic AA is D, E, and D, respectively, which is represented as [4D-8E-12D] here. As another form with three dispersed acidic AA positions, a [2D-6E-10D] peptide is also thought of. Moreover, as another form with a different acidic AA type, a [4E-8D-12E] peptide is also designed. We have simulated such peptides designed by the combination of [2-6-8]/[4-8-12] positions with $\mathrm{D} / \mathrm{E}$ acidic AAs.

Using the MM2-optimized structure of peptide 4 (Figure $4 \mathrm{D}$, structure one) as the initial structure, [4-8-12] peptides with different acidic AA were calculated. Similarly, [2-6-8] peptides were simulated. As the results, the [2-6-10] form was more stable than the [4-8-12] form; the [2D-6D-10D] peptide was the most stable structure (Figure 7). High Lu selectivity or Ln recovery yield peptides may be obtained due to increases in complex stability. By the application of the recovery yield simulation above, a peptide with Ln selectivity would be found, following a precipitation experiment which would evaluate and clarify the relationships between the Ln recovery performance, sequence, and calculation parameters. 


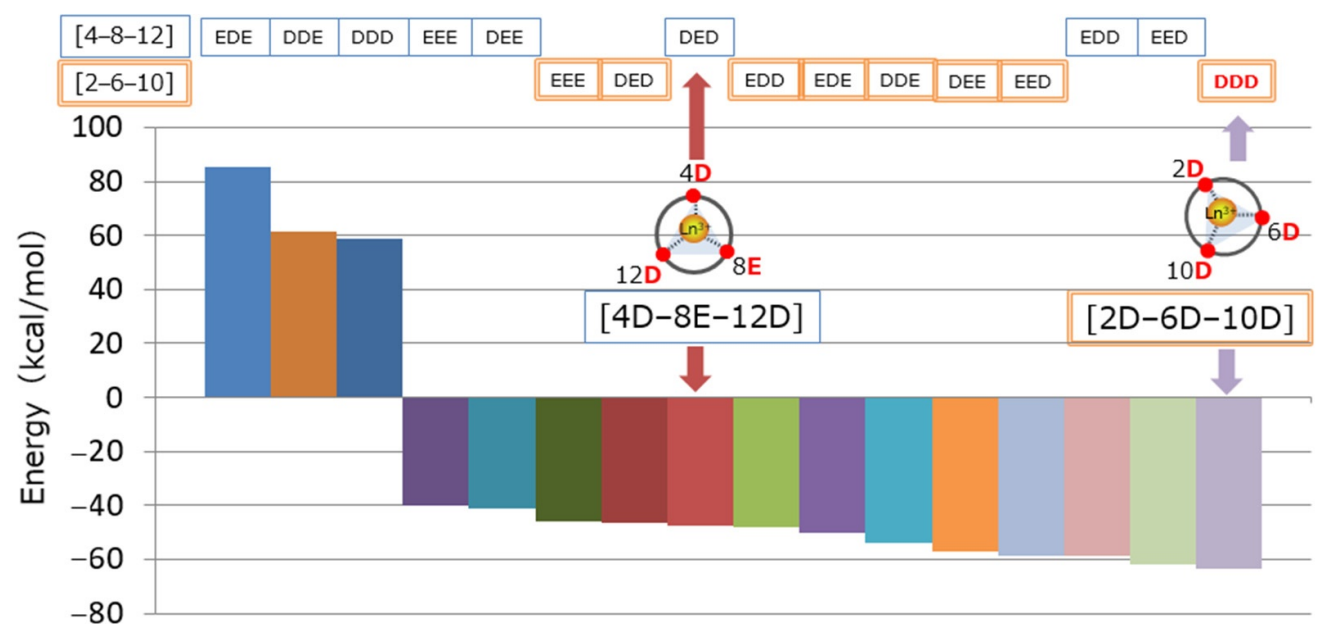

Figure 7. MM2 simulation results of various Ln complexes with different acidic AA/position of [4-8-12]/[2-6-10] peptides. Sequence for [4D-8E-12D]: CLWDGVSELFLDC; [2D-6D-10D]: CDLWGDVSLDFLC.

\section{Conclusions}

We designed, examined, and simulated the La, Dy, and Lu recovery performance of four new model cyclic peptide hosts bearing three acidic AAs at different positions. These hosts form 1:1 complex precipitates with $\mathrm{Ln}^{3+}$ via self-assembly. The recovery efficiency and selectivity depend on the position of the three acidic AAs; in particular, the $\mathrm{Lu}^{3+}$ recovery efficiency of peptide 4, which contains three AAs in a stable tripod arrangement, increased to $99 \%$. The unpredictable recovery efficiency/selectivity can be explained by considering a function based on the DM, LUMO, and CE. This screening method can be performed at a relatively low computational cost due to the solvent free condition. Additionally, we have proposed a leading peptide sequence via an MM2 calculation. The screening, by presenting an isolated yield simulation followed by a precipitation experiment, would clarify the correlation between the Ln recovery performance, sequence, and calculation parameters. This is the first step toward designing highly selective hosts and is expected to be applicable not only to the development of peptides for recovering Ln or other metal ions but also to the construction of diverse supramolecular systems based on complexation or self-assembly. Further investigations of the complexation mechanism, product structure, and novel peptide structures for improving the $\mathrm{Ln}^{3+}$ selectivity and developing advanced screening protocols are ongoing, and the results will be reported in due course.

Supplementary Materials: The following are available online at https: / www.mdpi.com/article/ 10.3390/min12020148/s1, Figure S1: Photographic images; Figure S2: ${ }^{1}$ H NMR spectra; Figure S3: ATR-FTIR spectra; Figure S4: ESI-MS spectra; Figure S5: TG-DTA chart; Figure S6: MM2 optimized structure of a1-5 in Figure 4; Figure S7: MM2 optimized structure of b1-5 in Figure 4; Figure S8: MM2 optimized structure of c1-5 in Figure 4; Figure S9: MM2 optimized structure of d1-5 in Figure 4; Figure S10: Dipole moment; Figure S11: LUMO orbital; Figure S12: Cohesive energy; Table S1: TG-DTA analysis data; Table S2: Isolated yield data; Table S3: ICP-OES yield data; Table S4: Total energy (kcal/mol) by MM2 calculations; Table S5: Re-calculated YD and YC; Table S6: Simulated yields data.

Author Contributions: Conceptualization, Y.H., T.H. and N.I.; methodology, Y.H.; software, Y.H.; validation, Y.H., T.H. and N.I.; formal analysis, Y.H. and A.O.; investigation, Y.H. and N.I.; data curation, Y.H. and A.O.; writing-original draft preparation, Y.H. and N.I.; writing-review and editing, Y.H., A.O., T.H. and N.I. All authors have read and agreed to the published version of the manuscript.

Funding: This research received no external funding. 
Acknowledgments: We thank Shuji Kajiya, Satoru Kosaka, and Mayu Kubota at the Toyota Central R \& D Labs., Inc. for their assistance with the ESI-MS, ICP-OES, and SEM-EDX experiments, respectively.

Conflicts of Interest: The authors declare no conflict of interest.

\section{References}

1. Binnemans, K.; Jones, P.T.; Blanpain, B.; Van Gerven, T.; Yang, Y.; Walton, A.; Buchert, M. Recycling of rare earths: A critical review. J. Clean. Prod. 2013, 51, 1-22. [CrossRef]

2. Hatanaka, T.; Matsugami, A.; Nonaka, T.; Takagi, H.; Hayashi, F.; Tani, T.; Ishida, N. Rationally designed mineralization for selective recovery of the rare earth elements. Nat. Commun. 2017, 8, 15670. [CrossRef]

3. Ishida, N.; Hatanaka, T.; Hosokawa, Y.; Kojima, K.; Iizuka, T.; Teramoto, H.; Sezutsu, H.; Kameda, T. Direct recovery of the rare earth elements using a silk displaying a metal-recognizing peptide. Molecules 2020, 25, 761. [CrossRef]

4. Bünzli, J.-C.G.; Piguet, C. Lanthanide-containing molecular and supramolecular polymetallic functional assemblies. Chem. Rev. 2002, 102, 1897-1928. [CrossRef]

5. Kanesato, M.; Yokoyama, T.; Suzuki, M.T. Reaction of tris(2-aminoethyl)amine coordinated to lanthanum(III) and gadolinium(III) with salicylaldehyde. Chem. Lett. 1997, 26, 93-94. [CrossRef]

6. Liu, Y.; Zhang, H.Y.; Bai, X.P.; Wada, T.; Inoue, Y. Molecular design of crown ethers. 21.(1,2) synthesis of novel double-armed benzo-15-crown-5 lariats and their complexation thermodynamics with light lanthanoid nitrates in acetonitrile. J. Org. Chem. 2000, 65, 7105-7109. [CrossRef]

7. Bogart, J.A.; Lippincott, C.A.; Carroll, P.J.; Schelter, E.J. An operationally simple method for separating the rare-earth elements neodymium and dysprosium. Angew. Chem. Int. Ed. 2015, 54, 8222-8225. [CrossRef]

8. $\quad$ Laine, S.; Morfin, J.-F.; Galibert, M.; Aucagne, V.; Bonnet, C.S.; Tóth, E. Lanthanide DO3A-complexes bearing peptide substrates: The effect of peptidic side chains on metal coordination and relaxivity. Molecules 2021, 26, 2176. [CrossRef]

9. Schmidtchen, F.P.; Berger, M. Artificial organic host molecules for anions. Chem. Rev. 1997, 97, 1609-1646. [CrossRef]

10. Bitta, J.; Kubik, S. Cyclic hexapeptides with free carboxylate groups as new receptors for monosaccharides. Org. Lett. 2001, 3, 2637-2640. [CrossRef]

11. Hamley, I.W. Small bioactive peptides for biomaterials design and therapeutics. Chem. Rev. 2017, 117, 14015-14041. [CrossRef] [PubMed]

12. Nitz, M.; Sherawat, M.; Franz, K.J.; Peisach, E.; Allen, K.N.; Imperiali, B. Structural origin of the high affinity of a chemically evolved lanthanide-binding peptide. Angew. Chem. Int. Ed. 2004, 43, 3682-3685. [CrossRef] [PubMed]

13. Cisnetti, F.; Gateau, C.; Lebrun, C.; Delangle, P. Lanthanide(III) complexes with two hexapeptides incorporating unnatural chelating amino acids: Secondary structure and stability. Chem. Eur. J. 2009, 15, 7456-7469. [CrossRef]

14. Kotynia, A.; Bielińska, S.; Kamysz, W.; Brasuń, J. The coordination abilities of the multiHis-cyclopeptide with two metal-binding centers-Potentiometric and spectroscopic investigation. Dalton Trans. 2012, 41, 12114-12120. [CrossRef] [PubMed]

15. Bar, A.K.; Kalita, P.; Singh, M.K.; Rajaraman, G.; Chandrasekhar, V. Low-coordinate mononuclear lanthanide complexes as molecular nanomagnets. Coord. Chem. Rev. 2018, 367, 163-216. [CrossRef]

16. Gahan, L.R.; Cusack, R.M. Metal complexes of synthetic cyclic peptides. Polyhedron 2018, 153, 1-23. [CrossRef]

17. Sherrington, D.C.; Taskinen, K.A. Self-assembly in synthetic macromolecular systems via multiple hydrogen bonding interactions. Chem. Soc. Rev. 2001, 30, 83-93. [CrossRef]

18. Zhao, X.; Pan, F.; Xu, H.; Yaseen, M.; Shan, H.; Hauser, C.A.E.; Zhang, S.; Lu, J.R. Molecular self-assembly and applications of designer peptide amphiphiles. Chem. Soc. Rev. 2010, 39, 3480-3498. [CrossRef]

19. Hamley, I.W. Peptide nanotubes. Angew. Chem. Int. Ed. 2014, 53, 6866-6881. [CrossRef]

20. Chan, W.-L.; Xie, C.; Lo, W.-S.; Bünzli, J.-C.G.; Wong, W.-K.; Wong, K.-L. Lanthanide-tetrapyrrole complexes: Synthesis, redox chemistry, photophysical properties, and photonic applications. Chemcal Soc. Rev. 2021, 50, 12189-12257. [CrossRef]

21. Celine, P.; Marilena, F.; Gadi, R.; Stefania, T. Lanthanide-Based Metal Organic Frameworks: Synthetic Strategies and Catalytic Applications. ACS Catal. 2016, 6, 6063-6072.

22. Muhammad, S.; Amr, G.; Mika, L.; Maarit, K. Lanthanide-based inorganic-organic hybrid materials for photon-upconversion. J. Mater. Chem. C 2020, 8, 6946-6965.

23. Ji, F.; Shao, S.; Li, Z.; Wang, S.; Chaudhuri, R.; Guo, Z.; Perkins, N.G.; Sarkar, P.; Xue, M. A cyclic peptide antenna ligand for enhancing terbium luminescence. Analyst 2021, 146, 3474-3481. [CrossRef] [PubMed]

24. Singer, H.; Drobot, B.; Zeymer, C.; Steudtner, R.; Daumann, L.J. Americium preferred: Lanmodulin, a natural lanthanide-binding protein favors an actinide over lanthanides. Chem. Sci. 2021, 12, 15581-15587. [CrossRef]

25. Hatanaka, T.; Kikkawa, N.; Matsugami, A.; Hosokawa, Y.; Hayashi, F.; Ishida, N. The origins of binding specificity of a lanthanide ion binding peptide. Sci. Rep. 2020, 10, 19468. [CrossRef]

26. Yoneya, M.; Yamaguchi, T.; Sato, S.; Fujita, M. Simulation of metal-ligand self-assembly into spherical complex M6L8. J. Am. Chem. Soc. 2012, 134, 14401-14407. [CrossRef]

27. Bonnet, C.S.; Fries, P.H.; Crouzy, S.; Sénèque, O.; Cisnetti, F.; Boturyn, D.; Dumy, P.; Delangle, P. A gadolinium-binding cyclodecapeptide with a large high-field relaxivity involving second-sphere water. Chem. Eur. J. 2009, 15, 7083-7093. [CrossRef] 
28. Brichtová, E.; Hudecová, J.; Vršková, N.; Šebestík, J.; Bouř, P.; Wu, T. Binding of lanthanide complexes to histidine-containing peptides probed by raman optical activity spectroscopy. Chem. Eur. J. 2018, 24, 8664-8669. [CrossRef]

29. Walsh, T.R. Pathways to structure-property relationships of peptide-materials interfaces: Challenges in predicting molecular structures. Acc. Chem. Res. 2017, 50, 1617-1624. [CrossRef]

30. Carvajal-Diaz, J.A.; Cagin, T. Electrophoretic transport of $\mathrm{Na}^{+}$and $\mathrm{K}^{+}$ions within cyclic peptide nanotubes. J. Phys. Chem. B 2016, 120, 7872-7879. [CrossRef]

31. Webster, A.M.; Peacock, A.F.A. De novo designed coiled coils as scaffolds for lanthanides, including novel imaging agents with a twist. Chem. Commun. 2021, 57, 6851-6862. [CrossRef] [PubMed]

32. Miao, J.; Descoteaux, M.L.; Lin, Y.-S. Structure prediction of cyclic peptides by molecular dynamics + machine learning. Chem. Sci. 2021, 12, 14927-14936. [CrossRef] [PubMed]

33. Damjanovic, J.; Miao, J.; Huang, H.; Lin, Y.-S. Elucidating solution structures of cyclic peptides using molecular dynamics simulations. Chem. Rev. 2021, 121, 2292-2324. [CrossRef] [PubMed]

34. Špadina, M.; Bohinc, K. Multiscale modeling of solvent extraction and the choice of reference state: Mesoscopic modeling as a bridge between nanoscale and chemical engineering. Curr. Opin. Colloid Interface Sci. 2020, 46, 94-113. [CrossRef]

35. Hosseinzadeh, P.; Bhardwaj, G.; Mulligan, V.K.; Shortridge, M.D.; Craven, T.W.; Pardo-Avila, F.; Rettie, S.A.; Kim, D.E.; Silva, D.-A.; Ibrahim, Y.M.; et al. Comprehensive computational design of ordered peptide macrocycles. Science 2017, 358, 1461-1466. [CrossRef]

36. Kuroda, Y.; Suenaga, A.; Sato, Y.; Kosuda, S.; Taiji, M. All-atom molecular dynamics analysis of multi-peptide systems reproduces peptide solubility in line with experimental observations. Sci. Rep. 2016, 6, 19479. [CrossRef]

37. Yanagisawa, S.; Yanagida, S. Density functional theory-based molecular modeling: Verification of decisive roles of van der waals aggregation of triiodide ions for effective electron transfer in wet-type N3-dye-sensitized solar cells. Energies 2020, $13,3027$. [CrossRef]

38. Cram, D.J. Preorganization—from solvents to spherands. Angew. Chem. Int. Ed. 1986, 25, 1039-1057. [CrossRef]

39. Yanagida, S. Density functional theory-based molecular modeling: Interaction analysis of PEG with metal ion. Wako Inform. World 2011, 25, 8-9.

40. Ohyoshi, E. Spectrophotometric determination of formation constants of 1:1 complexes of lanthanides with 4-(2-pyridylazo) resorcinol (par). Talanta 1984, 31, 1129-1132. [CrossRef]

41. Tsakanika, L.V.; Ochsenkühn-Petropoulou, M.T.; Mendrinos, L.N. Investigation of the separation of scandium and rare earth elements from red mud by use of reversed-phase HPLC. Anal. Bioanal. Chem. 2004, 379, 796-802. [CrossRef] [PubMed]

42. Itoh, J. Novel analytical applications of porphyrin to HPLC post-column flow injection system for determination of the lanthanides. Talanta 2006, 69, 61-67. [CrossRef] [PubMed]

43. Stewart, J.P. MOPAC: MOPAC2016, version 16.093W; Stewart Computational Chemistry: Colorado Springs, CO, USA, 2007; Available online: http:/ /OpenMOPAC.net (accessed on 1 May 2016).

44. Dassault Systèmes. BIOVIA Materials Studio, version 7.0/8.0; Dassault Systèmes: San Diego, CA, USA, 2018.

45. Dassault Systèmes. BIOVIA Modules Tutorials Materials Studio 2017; Dassault Systèmes: San Diego, CA, USA, 2016.

46. Mohamed, M.E. Synthesis and spectroscopic characterization of l-aspartic acid complexes with metals of the lanthanides family. Int. Lett. Chem. Phys. Astron. 2013, 11, 91-115. [CrossRef]

47. Shi, T.; Siu, K.W.M.; Hopkinson, A.C. Generation of [La(peptide)] $]^{3+}$ complexes in the gas phase: Determination of the number of binding sites provided by dipeptide, tripeptide, and tetrapeptide ligands. J. Phys. Chem. A 2007, 111, 11562-11571. [CrossRef] [PubMed] 